\title{
The utilization of the climatic chamber to evaluate the influence of ambient conditions on endocrine, nervous and immune systems of rats
}

\author{
Arkadiusz Baran $^{1,2}$, Grzegorz Jakiel ${ }^{1}$, Grażyna Wójcik ${ }^{2}$ \\ ${ }^{1}$ Department of Reproduction and Andrology, Medical University of Lublin, \\ ${ }^{2}$ Department of Human Physiology, Medical University of Lublin
}

\begin{abstract}
The adaptation of an organism to a change in environmental conditions is a complex and in some aspects a poorly understood physiological process. The activating influence of stress on the sympathetic nervous system, the hypothalamic - pituitary - adrenal axis and the suppression of TSH, LH, FSH release is well known. The interplay of communication between the endocrine and immune systems plays an essential role in modulating the response to stress related mediators. The basis of many contradictory and incoherent results of experiments is due to the various methodologies of creating changes in environmental conditions, the way of collecting blood samples which influence stress mediators, the case of assessing the influence of many factors on reproductive functions and the performance of experiments without synchronization with the reproductive cycle. The review will focus on the presentation of simple and repeatable methods of development of an adaptation stress to changed environmental conditions (temperature, oxygenation, humidity) and the technique of blood collection during hour-long estimation of interactions between the endocrine, nervous and immune systems. We would like to place emphasis on appropriate ways of performing experiments on female rats, with regards to the choice of a suitable phase of the reproductive cycle. Also on ways of anaesthesia and microsurgical techniques of vein catheterisation for repeated blood sampling. The performance of all phases of the experiment allow us to estimate only the influence of environmental conditions and eliminate interfering factors during the process of preparing animal for the experiment.
\end{abstract}

Key words: Climatic chamber - Acclimation - Collecting blood samples - Rat

\section{Introduction}

The adaptation of an organism to a change in environmental conditions is a complex and in some aspects poorly understood physiological process. The activating influence of stress on the sympathetic nervous system, the hypothalamic-pituitary-adrenal axis and the suppression of TSH, LH, FSH release is well known. The interplay communication between the endocrine and immune systems play an essential role in modulating the response to stress related mediators.

Advances in the field of neuroimmunology and more recently in psychoneuroimmunology have shown that central nervous system (CNS) and the immune system are intimately linked and do not function as independent systems [1]. The hypothalamo-

Correspondence: A. Baran, Dept. of Human Physiology, Medical University of Lublin, Radziwiłłowska Str. 11, 20-080 Lublin, Poland; tel./fax: (+4881) 5288405, e-mail: arkadiusz-baran@go2.pl -pituitary-adrenocortical (HPA) axis plays a vital role in adaptation of the organism to homeostatic challenge. Activation of the HPA system culminates in secretion of glucocorticoid, which act at multiple levels to redirect energy resources [2]. The end effects of glucocorticoids action include energy mobilization in the liver, suppression of innate immunity in immune organs, inhibition of bone and muscle growth, potentiation of sympathetic nervous system - mediated vasoconstriction, proteolysis and lipolysis, suppression of reproductive function along the hypothalamo-pituitary-gonadal axis and behavioural depression [3]. The HPA axis exerts an inhibitory effect on the female reproductive system [4]. In addition, the hypothalamic neuropeptide, corticotrophin releasing hormone $(\mathrm{CRH})$ and its receptors have been identified in most female reproductive tissues, including the ovary, uterus, and placenta. Furthermore, CRH is secreted in peripheral inflammatory sites where it exerts strong inflammatory actions [5]. The effects of catecholamines are mediated through adrenoreceptors and 
result in a wide range of physiological changes that best serve an animal in the face of imminent danger [6]. The presence of a close association between sympathetic nerve fibres and cells of the immune system could provide a direct mechanism enabling the CNS to regulate specific aspects of the immune response. Thus it appears that the CNS can communicate with the immune systems in a general sense via endocrine outflow from the CNS, adrenocorticotropine (ACTH), and glucocorticoids to the periphery, but also more directly by means of sympathetic innervation of both primary and secondary lymphoid organs [7]. Recent evidence shows an important role of the parasympathetic cholinergic pathway in the bidirectional communication between the brain and immune system [8-10]. The immune system may communicate with the CNS through immune products, primarily cytokines leading to direct CNS activation [11,12] or to release of CNSderived cytokines. Also, estrogens play an important role in immune modulation [13] and contribute to the approximately 2 - to 10 - fold higher incidence of autoimmune/inflammatory diseases seen in females of all mammalian species [14]. Several examples of evidence indicates that the positive or negative emotional state of the man or animal may influence immunological parameters via the limbic -hypothalamic circuits, which represents the neuropsychological background of emotionality. The communication between the periphery and brain takes place via both neural and hormonal pathways. Cytokines released by activated immune cells, in addition to their role in regulating cellular interactions, is one of the way by which the immune system communicates with the CNS and thereby influences behaviour. Interleukins: IL-1, IL-2, IL-6, TNF- $\alpha$ influence activation of the HPA axis and are, in turn, influenced by glucocorticoid secretion $[1,14]$.

Reproductive activity is one of the main functions that becomes altered and inactivates during the adaptive response to stress [15]. The result of experiments indicate that the effects of stress on sexual behaviour depend on the characteristics of the stressors [16]. Psychogenic stress can be a potent inducer of neuroendocrine mediators that suppress the immune system, and most studies have focused on these neurotransmitters and hormones and the subsequent signalling pathways [17]. The relatively small numbers of studies have emphasized or carefully considered quantitative aspects of stress-induced immunomodulation and have revealed useful information and suggest productive directions for future work. The review will focus on the presentation of simple and repeatable methods of the development of an adaptation stress to changed environmental conditions (temperature, oxygenation, humidity) and the technique of collecting blood during an hour-long estimation of interactions between the endocrine, nervous and immune systems.

\section{The climatic chamber}

The female Wistar rats (Rattus norvergicus) were tested ones at a time in the climatic chamber $[18,19]$. The climatic chamber (Multiserv model KBI - 100, Lublin, Poland) is a box with plexiglas walls of dimensions $50 \times 40 \times 40 \mathrm{~cm}$. Internal environmental parameters (oxygenation, temperature, humidity) are automatically adjustable and monitored. The acclimation in the climatic chamber started at 12 am and the animals remained in the climatic chamber for 30 minutes $[18,19]$. After the experiment, animals were returned to their cages. Before the experiment, three month old female rats, weighing 200 to $300 \mathrm{~g}$ were housed in standard cages, six per cage, in a controlled temperature room $\left(21^{\circ} \mathrm{C} \pm 1^{\circ} \mathrm{C}\right)$, with a $12 \mathrm{~h}$ light: $12 \mathrm{~h}$ dark cycle, lights were turned on at 6:00 am. Standard laboratory chow and tap water were available $a d$ libitum.

\section{The determination the phase of the estrous cycle}

During three months, every morning between 8:00 and 9:00 am an estimation of the vaginal lavage using a microscope was done to determine the phase of the estrous cycle. Unstained material was observed under a light microscope, without the use of the condenser lens, with 10 and $40 \times$ objective lenses. The short length of the estrous cycle of rats makes them useful for the investigation of changes occurring during the reproductive cycle. The estrous cycle lasts four days and is characterized as: proestrus, estrus, metestrus and diestrus, which may be determined according to the cell types observed in the vaginal smear. A proestrous smear consists of a predominance of nucleated epithelial cells; an estrous smear primarily consists of anucleated cornified cells; a metestrous smear consists of the same proportion among leukocytes, cornified, and nucleated epithelial cells, and a diestrous smear primarily consists of a predominance of leukocytes [20]. The proportion among cells is used for the determination of the estrous cycle phases [20]. The special significance of the proestrus phase of the estrous cycle of the rat, during which LH and FSH levels increase is known. Ovulation occurs from the beginning of proestrus to the end of the estrus $[21,22]$. The collection of vaginal lavage from the rats, is a very easy procedure but the determination of vaginal lavage should not be done in the presence of rats from other cages in order to avoid stress and lower the aggressiveness of females that will be caught afterwards [23].

The results of some studies show that reproductive function of rats is modified differentially, depending on the characteristics of each stressor and on the duration of exposure (acute or chronic) [16]. 


\section{The blood collection}

Investigation of preovulatory gonadotropin surges or other factors usually requires withdrawal of serial blood samples since the analysis of a single sample may be insufficient to detect the surges due to the variation in the time at which they occur. When the researchers decapitate the animals in their studies, the surges of some animals may be missed. So the best way to study the whole surge of any hormones or factors is hourly sampling, followed by vessel cannulation. Jugular vein catherization has been successfully used by investigators for more than a decade. Rats with jugular catheters exhibit low basal plasma stress hormones (adrenocorticotropin, corticosterone) and normal circadian activity [24]. The presence or absence of the jugular catheter did not affect the basal expression of the immediate early gene product Fosprotein in the brain $[25,26]$. Repeated blood sampling of $0.6 \mathrm{ml}$ at $0,10,30,60$ and 120 minutes [27] or of $0.25 \mathrm{ml}$ every 15 minutes for $9 \mathrm{~h}$ [28] followed by replacement of the same volume with $0.9 \% \mathrm{NaCl}$ has been shown not to alter the plasma concentration of prolactin, a hormone that responds to a variety of stressful stimuli [29]. It has been shown that secretion of adrenocorticotropin and corticosterone was not modified during withdrawal of 14 blood samples of $300 \mu \mathrm{l}$ from catheterized male rats [24]. Also serial blood sampling does not alter the magnitude of the LH and FSH surges [23]. It is necessary to anesthetize the rat for this procedure. If any experiment is performed one or more days before the proestrus phase in a regular cycling rat, it can alter the estrous cycle and one can no longer guarantee that the next proestrous will occur on the expected day [23]. If it is done in the late morning of proestrous after the pool of releasable GnRH has been synthesized and before the time of triggering the gonadotropin surges, which occurs around $12 \mathrm{am}$, it will not change the sequence and repeatability of the estrous cycle [30]. The best option is to first verify that the rat is in the proestrus phase and then perform anesthesia and vessel cannulation in the late morning of the same day.

The repeated blood sampling, regarding the activation of hypathalamo-pituitary-adrenal axis, seems to be a non-stressful method. These observations suggest that, when performed properly, catheterisation of the jugular vein does not lead to sensitization of stresssensitive neurocircuits.

\section{The method of anesthesia}

The selection of anesthetic is a crucial factor for the success of this sort of study. Some anesthetic can easily block the gonadotropin surges and also interfere with the amplitude of these surges. The female rats anesthetized with barbiturates during proestrus as well as on other days of the estrous cycle did not show either preovulatory gonadotropin surges during proestrous afternoon or ovulation on the next estrous morning $[23,31,32]$. Ketamine/xelazine or tiletamide/ zolazepam anesthesia also block the preovulatory surges of LH and FSH [23]. The previous data indicate that to produce adequate surgical anesthesia in cycling female rats without suppressing the preovulatory gonadotropin surges tribromoethanol should be used [33]. In rats, tribromoethanol anesthesia is recommended at a dose of 260 to $300 \mathrm{mg} / \mathrm{kg}$ body weight and given intra peritonealy [23]. The experimental data show that tribromoethanol at a dose of $250 \mathrm{mg} / \mathrm{kg}$ body weight alone or followed by jugular vein cannulation does not alter either the magnitude of the gonadotropin surges or the number of ova, suggesting that tribromoethanol is an ideal anesthetic for this sort of study [23]. The reason why tribromoethanol anesthesia does not prevent the occurrence of the gonadotropin surge is still unknown. One might hypothesize that tribromoethanol may have specific sites of action on the central nervous system which do not overlap with that responsible for the control of the gonadotropin surges or the actions of the excitatory neurotransmitters may be predominant over the inhibitory ones at the time of the surge. For long-term studies, the use of tribromoethanol anesthesia should not be recommended since some pathological changes such as abdominal visceral adhesion, hepatic capsular fibrosis and interstitial ileus have been reported $[34,35]$.

\section{Summary}

In conclusion, the method described and validated in this study: utilization of a climatic chamber, jugular vein catherization under tribromoethanol anesthesia followed by serial blood sampling, is suitable to evaluate time course of some factors released in the afternoon during proestrous phase.

Acknowledgements: This study was supported by grant from Medical University of Lublin (PW 224/07).

\section{References}

[ 1] Wrona D. Neural-immune interactions: an integrative view of the bidirectional relationship between the brain and immune systems. J Neuroimmunol. 2006;172:38-58.

[2] McEwen BS, Stellar E. Stress and the individual. Mechanisms leading to disease. Arch Intern Med. 1993;153:20932101.

[ 3] Herman JP, Larson BR, Speert DB, Seasholtz AF. Hypothalamo-pituitary-adrenocortical dysregulation in aging F344/ Brown-Norway F1 hybrid rats. Neurobiol Aging. 2001;22: 323-332.

[4] Chrousos GP, Torpy DJ, Gold PW. Interactions between the hypothalamic-pituitary-adrenal axis and the female reproductive system: clinical implications. Ann Intern Med. 1998; 129:229-240. 
[5] Kalantaridou SN, Makrigiannakis A, Zoumakis E, Chrousos GP. Reproductive functions of corticotropin-releasing hormone. Research and potential clinical utility of antalarmins (CRH receptor type 1 antagonists). Am J Reprod Immunol. 2004;51:269-274.

[ 6] Tayebati SK, Bronzetti E, Morra DC, et al. In situ hybridization and immunocytochemistry of alphal-adrenoceptors in human peripheral blood lymphocytes. J Auton Pharmacol. 2000;20:305-312

[ 7] Shimizu N, Hori T, Nakane H. An interleukin-1 beta-induced noradrenaline release in the spleen is mediated by brain corticotropin-releasing factor: an in vivo microdialysis study in conscious rats. Brain Behav Immun. 1994;8:14-23.

[ 8] Tracey KJ. The inflammatory reflex. Nature. 2002;420:853859.

[ 9] Pavlov VA, Wang H, Czura CJ, Friedman SG, Tracey KJ. The cholinergic anti-inflammatory pathway: a missing link in neuroimmunomodulation. Mol Med. 2003;9:125-134.

[10] Saeed RW, Varma S, Peng-Nemeroff T, et al. Cholinergic stimulation blocks endothelial cell activation and leukocyte recruitment during inflammation. J Exp Med. 2005;201:11131123.

[11] Berkenbosch F, van Oers J, del Rey A, Tilders F, Besedovsky $\mathrm{H}$. Corticotropin-releasing factor-producing neurons in the rat activated by interleukin-1. Science. 1987;238:524-526.

[12] Sapolsky R, Rivier C, Yamamoto G, Plotsky P, Vale W. Interleukin-1 stimulates the secretion of hypothalamic corticotropin-releasing factor. Science. 1987;238:522-524.

[13] Sapino A, Cassoni P, Ferrero E, et al. Estrogen receptor alpha is a novel marker expressed by follicular dendritic cells in lymph nodes and tumor-associated lymphoid infiltrates. $\mathrm{Am} \mathrm{J}$ Pathol. 2003;163:1313-1320.

[14] Sternberg EM. Neuroendocrine regulation of autoimmune/inflammatory disease. $J$ Endocrinol. 2001;169: 429-435.

[15] Johnson E. Mechanisms of stress: a dynamic overview of hormonal and behavioral homeostasis. Neurosci Biobehav Rev. 1992;16:115-130.

[16] Retana-Marquez S, Bonilla-Jaime H, Vazquez-Palacios G, Martinez-Garcia R, Velazquez-Moctezuma J. Changes in masculine sexual baehavior, corticosterone and testosterone in response to acute and chronic stress in male rats. Horm Behav. 2003;44:327-337.

[17] Pruett SB, Fan R, Myers LP, Wu WJ, Collier S. Quantitative analysis of the neuroendocrine-immune axis: linear modeling of the effects of exogenous corticosterone and restraint stress on lymphocyte subpopulations in the spleen and thymus in female B6C3F1 mice. Brain Behav Immun. 2000;14:270-287.

[18] Baran A, Jankiewicz M, Wójcik G, Borowicz B, Jakiel G. Short stay in ambient hypoxia increases plasma interleukin-6 level in mice. Pol J Environ Stud. 2006;15-3A:55-58.

[19] Baran A, Jankiewicz M, Wójcik G, Borowicz B, Jakiel G. Temperature-induced increase of plasma interleukin 6 in mice during short period of adaptation to novel climatic conditions. Pol J Environ Stud. 2006;15-3A:148-150.

[20] Mandl A.M. The phases of the oestrous cycle in the adult white rat. J Exp Biol. 1951;28:584-588.
[21] McClintock JA, Schwartz NB. Changes in pituitary and plasma follicle stimulating hormone concentrations during the rat estrous cycle. Endocrinology. 1968;83:433-441.

[22] Schwartz NB, Bartosik D. Changes in pituitary LH content during the rat estrous cycle. Endocrinology. 1962;71:756762.

[23] Poletini MO, Szawka RE, Freitas Marcon RM, Veiga MD, Franci CR, Anselmo-Franci JA. A method to study preovulatory surges of gonadotropins. Brain Res Brain Res Protoc. 2003;12:41-48.

[24] Thrivikraman KV, Huot RL, Plotsky PM. Jugular vein catheterization for repeated blood sampling in the unrestrained conscious rat. Brain Res Brain Res Protoc. 2002;10:84-94.

[25] Thrivikraman KV, Nemeroff CB, Plotsky PM. Sensitivity to glucocorticoid-mediated fast-feedback regulation of the hypothalamic-pituitary-adrenal axis is dependent upon stressor specific neurocircuitry. Brain Res. 2000;870:87-101.

[26] Thrivikraman KV, Su Y, Plotsky PM. Patterns of FosImmunoreactivity in the CNS Induced by Repeated Hemorrhage in Conscious Rats. Correlations with Pituitary-Adrenal Axis Activity. Stress. 1997;2:145-158.

[27] Lawson DM, Gala RR. The influence of surgery, time of day, blood volume reduction and anaesthetics on plasma prolactin in ovariectomized rats. J Endocrinol. 1974;62:75-83.

[28] Demling J, Fuchs E, Baumert M, Wuttke W. Preoptic catecholamine, GABA, and glutamate release in ovariectomized and ovariectomized estrogen-primed rats utilizing a push-pull cannula technique. Neuroendocrinology. 1985;41:212-218.

[29] Gala RR. The physiology and mechanisms of the stressinduced changes in prolactin secretion in the rat. Life Sci. 1990;46:1407-1420.

[30] Levine JE. New concepts of the neuroendocrine regulation of gonadotropin surges in rats. Biol Reprod. 1997;56:293-302.

[31] Dominguez R, Smith ER. Barbiturate blockade of ovulation on days other than proestrus in the rat. Neuroendocrinology. 1974; 14:212-223.

[32] Kalra SP, Simpkins JW, Kalra PS. Progesterone-induced changes in hypothalamic luteinizing hormone-releasing hormone and catecholamines: differential effects of pentobarbital. Endocrinology. 1981;108:1299-1304.

[33] Anselmo-Franci JA, Franci CR, Krulich L, AntunesRodrigues J, McCann SM. Locus coeruleus lesions decrease norepinephrine input into the medial preoptic area and medial basal hypothalamus and block the LH, FSH and prolactin preovulatory surge. Brain Res. 1997;767:289-296.

[34] Norris ML, Turner WD. An evaluation of tribromoethanol (TBE) as an anaesthetic agent in the Mongolian gerbil (Meriones unguiculatus). Lab Anim. 1983;17:324-329.

[35] Reid WC, Carmichael KP, Srinivas S, Bryant JL. Pathologic changes associated with use of tribromoethanol (avertin) in the Sprague Dawley rat. Lab Anim Sci. 1999;49:665-667.

Submitted: 25 January, 2008 Accepted after reviews: 21 March, 2008 